\title{
The role of "Engineering Marketing" study course in raising the prestige of market-minded engineers in the context of digital economy
}

\author{
Tatiana Lyubanova ${ }^{1, *}$, Lidia Shcherba ${ }^{1}$, Valery Lisitsin ${ }^{1}$ and Yulia Oleynikova ${ }^{1}$ \\ ${ }^{1}$ Don State Technical University, Rostov-on-Don, Russia
}

\begin{abstract}
On the one hand, engineering marketing is a new and groundbreaking paradigm in marketing evolution in national practice, which helps to integrate design and engineering competencies with market mindset. On the other hand, the study course "Engineering Marketing" is intended for development of a new knowledge type, new cross-disciplinary style as a symbiosis of scientific thought and market ideology providing a way to create a market-minded generation of engineers capable of developing technology entrepreneurship taking into account scientific and technological progress. The concept of engineering marketing toolkit is developed by the authors in the form of engineering marketing mix formula $(\mathrm{EMM}=\mathrm{f}(\mathrm{nP}))$ considering its evolutionary changes and engineering marketing business model is presented including corresponding impact effects of engineering solutions on the target market using the psycho heuristic programming method. In the digital economy such a tool in the engineering marketing mix as processing acquires particular importance assuming the use of information technologies and systems, including engineering software, at all stages of engineering activity. Furthermore, it is easier to transform the existing infrastructure of an industrial enterprise into digital one with the help of special IoT platform using the relevant engineering software.
\end{abstract}

\section{Introduction}

One of the main areas of the research conducted by the authors, contributing to innovative activity, competitiveness and increased productivity, is the development of engineering marketing mechanism designed to significantly increase the efficiency of marketing in engineering activity.

Engineering marketing, according to the authors, is a new paradigm in marketing evolution which determines the corresponding requirements for engineering personnel. Currently, an engineer should be a generator of progress, since it is engineer who, first and foremost, has the ability to integrate the enterprise's potential and market needs through technical solutions providing the prospect for stakeholders to participate in development and adaptation of goods and services. In this case, the paradigm of engineering marketing, as noted by the authors in their studies [1,2], becomes crucial for Russian economy in order to

*Corresponding author: oferta2008@mail.ru 
develop the market mindset of staff, including engineers, which largely involves commercialization and development of technology business.

In the context of digital economy formation, the task of efficient management of scientific and technical innovations at manufacturing ventures can be solved by building mechanisms for innovative development of science and technology. Currently, scientific and technological progress determined by the efficiency of innovations, which is directly dependent on their effective management, is acquiring qualitatively new features:

- firstly, the scope of the use has changed rapidly;

- secondly, the fundamental restructuring of industrial production, organization and management of production processes takes place;

- thirdly, the computer revolution, changing the nature of technology-based business, made it possible to operate machines and manage production processes with the use of computers and other electronic devices;

- fourthly, a lot of new engineering software and various kinds of software platforms have recently appeared.

Ultimately, the focus will be on artificial intelligence, teaching machines, smart production, related equipment and products, as well as on the creation of the powerful, human-centred market state.

\section{Materials and methods}

The theoretical and methodological basis for the formation of ways of interaction between business structures, knowledge-intensive industries, scientific and technical areas of building products and processes using marketing, practical issues of science, technology and innovation development are considered in the papers of a number of foreign authors (Inzelt A. Csonka I., Miles I., Seidl da Fonseca R., Pinheiro-Veloso A.) [3, 4, 5]. It should be noted that the studies of engineering marketing problems cannot be found in foreign scientific papers. The issues of the formation of human capital, namely, engineers and technicians, necessary for transition to the knowledge economy and information society [6] are studied in the domestic scientific community (Litvintseva G.P., Nizovkina N.G., Gakhova N.A.). A number of Russian researchers (Leushin I.O., Leushina I.V., Antonenko N.A., Asaeva T.A., Tikhonova O.V., Grechushkina N.V.) studied the marketing approach in the engineering personnel education, applied marketing customization tools to address adaptation of graduates to the requirements of specific employers, which, however, did not provide for the introduction of a specific marketing course into the educational process [7, 8]. In turn, Zobnina M., Korotkov A., Rozhkov A., Tolmachev D.E., Chukavina K.V., Chepurenko A.Y. in their works studied the possibilities of entrepreneurial education development in Russian universities, examined the relevance of development of such educational directions as technology entrepreneurship [9, 10, 11]. These studies are characterized by the sufficiently detailed subject and cover a wide variety of business-related disciplines which does not allow extrapolating the results obtained to the target-oriented subject of engineering marketing.

It seems that it is necessary to consider approaches to the development of marketing model of engineering marketing in an integrated fashion, including the study course, which is particularly relevant from the perspective of the Program "Digital Economy of the Russian Federation". One of the objectives stated in the Program is to create an ecosystem of digital economy of the Russian Federation, in which effective interaction between business, scientific and educational community, government and citizens will be provided [12].

The studies of labor market trends confirm the importance of multifaceted engineering education, including acquisition of entrepreneurial skills [13].

The analysis of "marketing" term definitions showed that various scholars determine its content differently, but the basis is plurality, independence and self-sufficiency. This 
approach, according to the authors, is characterized, firstly, by the introduction of separate areas of marketing activity (marketing communications, market research, marketing methods and models, etc.); secondly, by the introduction of independent disciplines such as "Engineering Consulting", "Banking Marketing" and suggested by the authors "Engineering Marketing"; thirdly, by the need of marketing integration with the existing disciplines such as "Economics", "Management", "Sociology", "Psychology", "Information Science" and others [1].

It should be noted that the authors have interpreted the content of engineering marketing in different ways over time while retaining the original essence. So, according to the semantics of the phrase the authors came to the conclusion that engineering marketing consists in marketing orientation of engineering activity. Then it was considered in more detail at all stages of engineering activity which made it possible to make an assumption about engineering marketing as a driving force for industrial enterprise technological development, both from the point of view of research, development, preproduction, and in terms of the sale of goods and their use by consumers applying engineering solutions.

Successful commercialization of technical innovations requires the engineer not only to have technical competence, but also to have market mindset. In addition, marketers and engineers often do not understand each other and do not really try to find common ground. Conflicts between them happen because each department is focused only on its specific activity and its own success: engineers - mostly on the development and production of products, marketers - on the sale of goods. Everyone tries to increase the recognition of his work in the process. The problems could be solved in some extent if marketing department carried out its integrating and coordinating role and engineers had adequate market knowledge that could improve their interaction.

More successful interaction between engineers and marketers, described by the authors of the paper [1], is possible when engineers acquire additional market competencies. In this respect, the concept of engineering marketing was developed in 2011 as the philosophy of managing innovations outstripping scientific and technological progress based on the market mindset of engineers in all areas of engineering activity. In addition, the authors are known as the originators of engineering marketing concept as a revolutionary tool for entrepreneurship in the engineering environment with a view to creating a market-minded generation of engineers with entrepreneurial skills capable of developing technology business at all engineering stages, using all resources and appropriate engineering software, which is especially important today in the context of digital economy building. The task of engineering software companies is to provide interested industrial enterprises, including small businesses, with appropriate platforms for continuous innovations in the application of relevant tools that harmonize production in terms of social impact.

Further research on engineering marketing was focused on the problems of world globalization, which allowed the authors to suggest Russian globalization given the enormous scale of our country. It seems interesting that in current conditions, especially for corporate entities, it is useful to build so-called "integrated hybrid industrial production" which implies unifying processes of product development by various companies belonging to the corporation, but located in different regions and industries, on the basis of efficient value chain management. At the same time, the joint interest is important for creation of the "integrated hybrid production": some companies have information technologies and systems, engineering software; others have additive innovative technologies and related equipment, innovative materials, creative staff, development strategies, etc.

Under this approach, synergistic effect is created that makes it possible to augment all the good things of engineering activities of various companies.

In view of the above, in 2015 the authors supplemented the content of engineering marketing as follows: engineering marketing of industrial corporation is the philosophy of 
managing scientific and technological innovations within the entire value chain in all areas of engineering. The value chain provides for the optimization of engineering activities and costs by distributing them among many companies across different industries and regions. Therewith, the value chain is presented as a pyramid, at the base of which lie the technical competence of engineer scientists and designers, advanced technologies, innovative materials, etc., following the chain and creating "integrated hybrid production", that in foreign practice is understood as "physical production". In addition, the dispersal of value chain across regions and industries can provide the national globalization, thereby creating Russian technological parity.

\section{Results}

Particularly meaningful, in our opinion, is laying the emphasis on the companies involved in development of knowledge products with a view to research and development in engineering activity. Considering that Russia is the country of engineers, where fundamental and applied research has always been carried out, it is necessary to revitalize scientific schools, research laboratories and interdisciplinary institutes, as well as to pay more attention to small and medium business with high research potential. Such companies can be found in our big country and some of them follow the newest world trends, for instance, St. Petersburg firms, the activity of which includes research and development in the field of natural, technical and other sciences. For example, the company OOO "IOFFELED" is active firm, registered 15 years ago, that develops and produces diode sources (light-emitting diodes) and radiation receivers (photodiodes), as well as infrared sensors, etc. In addition, the company practices such activities as "production of tools and instruments for measurement, testing and navigation", "consulting in the domain of commercial activities and management", etc. Notably, the average number of employees was only 9 people in 2018 and 11 people in 2019. According to the Federal Tax Service, in 2018 the company's revenue reached 15.5 million rubles, and in 2019 it increased more than one and a half times - to 24.4 million rubles [14].

Another small company - OOO "MULTITECH" - "CONTROL MODULES AND LASER TECHNOLOGY" deals with a wide range of such activities as: "development of industrial processes and production projects regarding electrical engineering, electronic engineering, mining, chemical technology, mechanical engineering, and also industrial construction, systems engineering and safety". Furthermore, it is appropriate to mention such activities as "activities in the field of metrology", "advisory activities and computer technology works", "computer software development", "environmental pollution monitoring activities for individuals and entities". The company has been on the market for 20 years, which confirms its sustainability. The average staff number is 11 people in 2018 and 10 people in 2019, the amount of revenue is 4.9 million rubles in 2018 and 3.7 million rubles in 2019. It should be pointed out that OOO "MULTITECH" conducts research and has full technological cycle of laser precision processing of materials. In processing plants of the "POLYFER" type, a solid-state flashlamp-pumped laser of medium power is used, which allows conducting precision cutting and engraving of metals and alloys, ceramics, silicon and other opaque materials [15]. This may be extensively used in such industries as militaryindustrial complex, mechanical engineering and others.

The innovative solutions of many companies confirm the need to apply engineering marketing, which the authors also consider as the art and philosophy of selection of scientific and technical innovations, including in software development for automating research and development, business processes, PLM systems of product lifecycle management, etc. in close cooperation with researchers, programmers and market-minded engineers.

As evidenced by the Japanese experience, the method of conducting collaborative research in different regions, i.e. work of a big team had demonstrated its effectiveness and, 
it seems to us, that such teamwork can attract creative young people and private capital to many regions. In this regard, it is worth to mention the statement of Akio Morita, the former president of the Sony Company, "business is not an individual game, it is a teamwork. Nothing can be achieved without harmonious cooperation" [1]. In addition, this approach will lead to alignment of innovative research and development and other types of engineering across different regions and industries. The result will be seen in turning-on "collective brain" and increasing competitiveness of products and enterprises both in the regions and in the whole country.

The authors also point out that enterprise management and engineering staff need to pay special attention to product quality adopting the philosophy of Edwards Deming [1,2] and new market orientation of products from the standpoint of quality, which can be transformed into marketing ideology as ideology of the future ("Cooperation: everyone wins!"). In the context of Russian globalization and digital economy formation, such ideology makes it possible to organize teamwork in different regions and industries "for the benefit of the whole company", i.e. in a single information hub, when the competitiveness of the whole national industry can be reached.

Engineering marketing should become the driver of technology entrepreneurship development, considered as a modern managerial concept designed for, primarily, enterprise management and engineering personnel, forming their line of thinking and course of action.

According to the authors, in order to implement this suggestion in technical universities, it is advisable to introduce a new study course "Engineering Marketing" in national and foreign practice and organize education of market-minded engineers who will be able to develop and make technical decisions from the position of commercialization and technology entrepreneurship.

The importance of proposed study course is shown with the use of its marketing model compiled by the authors as a "logically structural framework" based on the "molecular model of marketing of services", developed by Lynn Shostack [1] and applied in foreign practice. This approach has been used by the authors for many years for purposes of economic and market justification of developed technical and technological solutions and scientific research in course works and degree projects of science and technology students (bachelors, specialists, masters, postgraduate students) of Don State Technical University.

The marketing model of "Engineering Marketing" study course can include following components:

- idea, that shows the purpose of the research conducted in order to develop a new study course, i.e. the main benefit;

- implementation version which should be understood as a result of materialization of the author's idea;

- scope includes possible areas of application of engineering marketing research results;

- competition shows which national and foreign similar studies were conducted and by whom;

- engineering marketing tools, that is, first of all, an "integrated metrics" of engineering marketing mix, including identification of marketing tools through engineering solutions, their consideration both individually and as a group, as well as building the business model of engineering marketing;

- calculation methods include computational and analytical methods, other research methods, applied in engineering marketing;

- engineering marketing evolutionary development consists in its consideration and adaptation in accordance with the changes of the contemporary world;

- consumer benefits include benefits of suggested study course use for all of its customers;

- producer benefits include the benefits for the developers of a new study course. 
Considering the above, the marketing model of "Engineering Marketing" study course is shown in Figure 1.

1. Idea:

- scientific and practical view of marketing in engineering activity;

- a way to create a generation of market-minded engineers;

- increase of the role and prestige of engineer.

2. Version of implementation:

- introduction of the new study course "Engineering Marketing" for technical universities;

- graduation of market-minded engineers in all technical fields of study;

- presidential program of engineering marketing for CEO and engineering personnel.

3. Scope:

- technical universities;

- different industries.

4. Competition:

- there are no competitors developing the scientific concept and ways of practical implementation of "Engineering Marketing" study course.

5. Engineering marketing tools:

- engineering marketing mix (EMM) as a set of marketing tools for entering target markets using engineering solutions. The formula of engineering marketing is given as a function of many variables in their evolutionary development, i.e. $E M M=f(7 P), E M M=f(9 P), E M M$ $=\mathrm{f}(11 \mathrm{P}), \mathrm{EMM}=\mathrm{f}$ (" $\mathrm{n}$ "P), where " $\mathrm{n}$ " is the number of variables. EMM includes marketing tools used for implementation of professional duties of market-minded engineers and provides for the development of technology entrepreneurship. The essence of EMM does not lie in the number of variables, but includes current transformation of engineering staff activities, their constant adaptation to the changing market environment and comprehensive movement towards continuous improvement of engineering solutions in conjunction with the transition to the digital economy;

- business model that makes it possible to analyze various situations and efficiently select technical solutions both for individual elements and for the model as a whole.

6. Methods applied in engineering marketing:

- engineering software;

- business modelling in engineering activity;

- psycho heuristic programming;

- other methods.

7. Engineering marketing evolutionary development:

- engineering marketing in digital economy conditions;

- adaptation of engineering marketing course according to the current requirements.

8. Benefits for "Engineering Marketing" course developers (authors):

- communication with technical universities;

- publications on engineering marketing, including monographs;

- diploma of winner of the I All-Russian Innovative Public Contest for the best course book, study guide and monograph (No OK000206 dated November 25, 2014) in the nomination for the best scientific monograph with the work "Engineering Marketing as a Tool to Increase the Efficiency of Industrial Enterprises' Development”. 


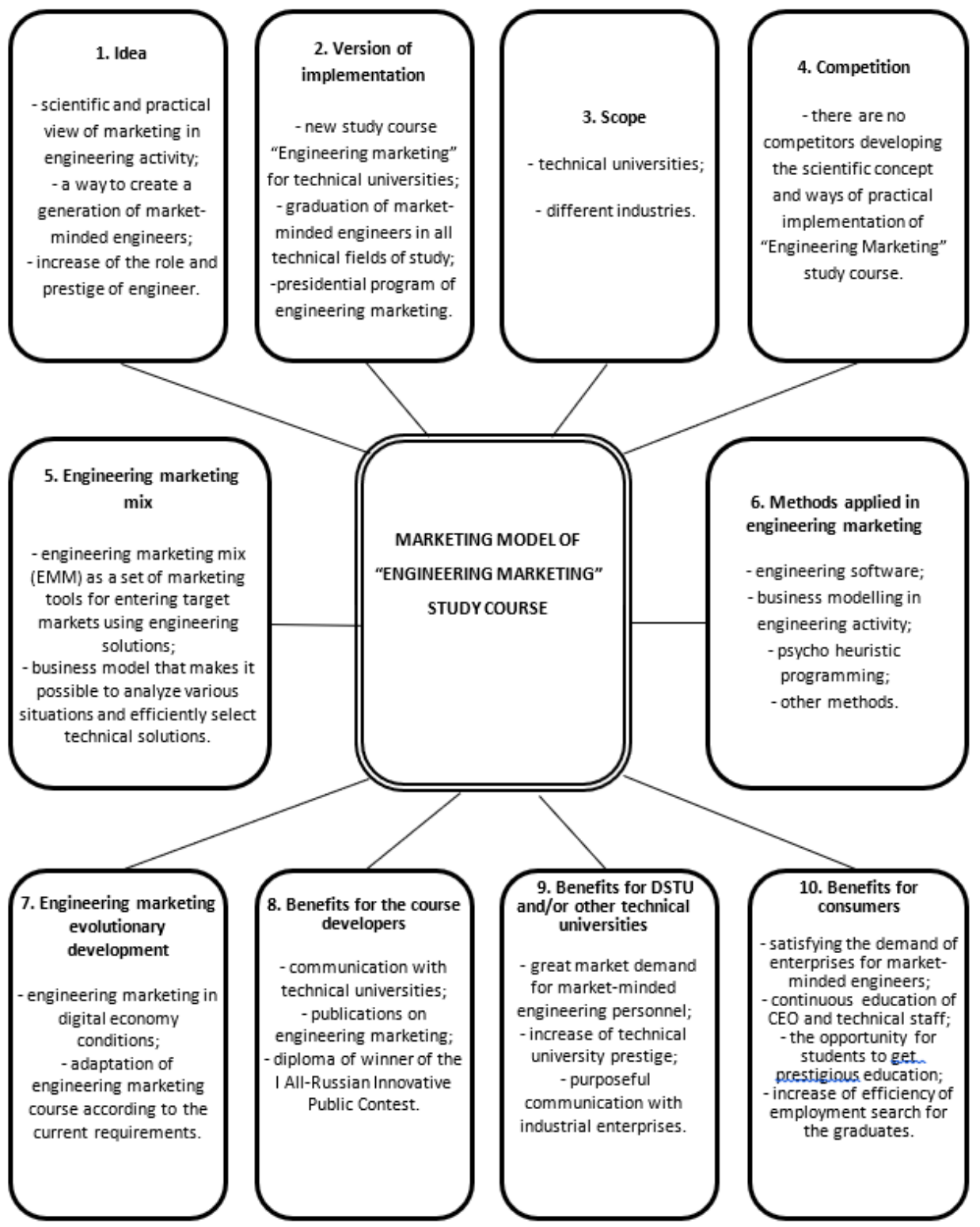

Fig. 1. The marketing model of "Engineering Marketing" study course.

9. Benefits for DSTU and/or other technical universities:

- great market demand for market-minded engineering personnel;

- increase of technical university prestige;

- purposeful communication with industrial enterprises.

10. Benefits for consumers:

10.1. for industrial enterprises:

- satisfying the demand of enterprises for market-minded engineers;

- continuous training of CEO and engineering staff in the field of engineering marketing in its evolutionary development according to present-day requirements.

10.2. for students: 
- the opportunity to get prestigious engineering education with marketing competences;

- increase of employment search efficiency.

The presented marketing model of "Engineering Marketing" study course makes it possible to understand its goal and significance for the economy in the context of digitalization, since the degree of economy innovativeness can be defined by the imperative of technical and technological restructuring, which depends on the appropriate ratio of professional and market competencies of the staff, particularly, engineering personnel. It seems that the imbalance of professional and entrepreneurial competencies can be considered as one of the reasons for the lack of competitiveness of industrial enterprises.

\section{Discussion}

The ancient Chinese proverb from the 7th century BC read: "If you're planning for a year, then sow the seeds. If you're planning for decades, then plant trees. If you think about the long-term vision, then educate people and develop their skills and abilities" [1]. It is from this position that building competencies in the field of engineering marketing for employees of technical departments becomes a creative and innovative approach, since the development of technology entrepreneurship and enterprise effective operation depend on their professional training.

From this perspective, Russian technical universities need to use the study course "Engineering Marketing" intended for interdisciplinary education of engineering personnel of all areas of engineering activity.

According to the authors, education should have a certain outcome. The coronavirus and pandemic, which have arisen in the world, have actually confirmed the need for broader education of paramedical personnel, doctors, also focused on interdisciplinary training, and made scientists think about introducing a wider range of study courses into educational programs in various fields of science.

The situation is similar in the field of engineering education. The crisis arising in the global economy necessitates the need for highly professional engineering personnel with marketing competencies capable of adapting products to the dynamic requirements of the market. This applies not only to medicine, but also to engineering.

Furthermore, the formation of digital economy should be based on a new generation of market-minded engineers capable of systems thinking and prepared to search for professional solutions of complex engineering problems and develop digital technologies in industry and everyday life.

\section{References}

1. T.P. Lubanova, D.M. Zozulya, L.M. Myasoedova, L.M. Sherba, N.N. Shumskaya, Engineering Marketing as a New Paradigm in Marketing Evolution and Innovative Tool of Enterprise Development (Don State Technical University, Rostov-on-Don, 2011)

2. T.P. Lubanova, D.M. Zozulya, Engineering Marketing as a Tool to Increase the Efficiency of Industrial Enterprises' Development (LAP LAMBERT, Saarbrücken, 2012)

3. A. Inzelt, I. Csonka, Foresight and STI Governance 11(4), 63-73 (2017) DOI: 10.17323/2500-2597.2017.4.63.73

4. I. Miles, V. Belousova, N. Chichkanov, Foresight and STI Governance 11(3), 94-102 (2017) DOI: 10.17323/2500-2597.2017.3.94.102 
5. R. Seidl da Fonseca, A. Pinheiro-Veloso, Foresight and STI Governance 12(2), 6-22 (2018) DOI: 10.17323/2500-2597.2018.2.6.22

6. G.P. Litvintseva, N.G. Nizovkina, N.A. Gakhova, The Education and Science Journal 19(2), 101-123 (2017) DOI: 10.17853/1994-5639-2017-2-101-123

7. I.O. Leushin, I.V. Leushina, Higher Education in Russia 7 (2020) DOI: https://doi.org/10.31992/0869-3617-2020-29-7-56-63

8. N.A. Antonenko, T.A. Asaeva, O.V. Tikhonova, N.V. Grechushkina, Higher Education in Russia 5 (2020) DOI: https://doi.org/10.31992/0869-3617-2020-29-5-144-156

9. M. Zobnina, A. Korotkov, A. Rozhkov, Foresight and STI Governance 13(4), 69-81 (2019) DOI: 10.17323/2500-2597.2019.4.69.81

10. D.E. Tolmachev, K.V. Chukavina, Economy of Region 16(2), 420-434 (2020) DOI: http://doi.org/10.17059/2020-2-7

11. A.Y. Chepurenko, Educational Studies Moscow 3, 248-276 (2017) DOI: 10.17323/1814-9545-2017-3-250-276

12. The Program "Digital Economy of the Russian Federation", http://static.government.ru/media/files/9gFM4FHj4PsB79I5v7yLVuPgu4bvR7M0.pdf

13. I. Artyushina, Higher Education in Russia 6, 28-32 (2006)

14. SBIS - business communication network, https://sbis.ru/contragents/7802327420/780201001

15. SBIS - business network, https://sbis.ru/contragents/7826042705/783901001 